\title{
Deployment of Vanets Infrastructure to Aid Road Transport Systems in Developing Countries
}

\author{
S. Konyeha and E. Osa
}

\begin{abstract}
This work proposes the adoption of Vehicular AdHoc Network (VANET) into the Road Transport system of developing countries. There are myriads of challenges to road transportation in developing countries which include poor state of roads, poor maintenance of roads, road congestions amongst others. The negative impacts of these developments could be very devastating on human lives as well as the economy of the nations concerned. Intelligent Transportation Systems (ITSs) which involve the integration of modern communication and information technology into existing transportation systems for real time monitoring of traffic in order to alleviate traffic congestion, incidents, public health issues, etc. Utilizing VANET communication infrastructure will enable ITSs to improve safety of commuters on the roads and minimize traffic congestion, waiting times, fuel consumption, and emissions. The situation in the Nigerian State is considered.
\end{abstract}

Index Terms - VANET; Intelligent, Transportation, System; Communication; Traffic.

\section{INTRODUCTION}

Metropolitan cities in the recent time have grown to the point where the present transportation infrastructures are no longer enough to cater for the masses. Up to 1970s in Nigeria, it was relatively easy to move from one part of the city to the other [1]. Within a period of approximately two decades, urban transportation systems have metamorphosed into a chaotic, complex and almost intractable haze in a manner that renders most cities almost to a state of relative immobility. Almost every urban centre in the developing countries today is confronted with transportation challenges that seem to grow worse over time. Road transport system is the most common mode of transportation in Nigeria. Traffic on the road depends on the pattern of human settlements and accounts for more than 90 per cent of the sub-sector's contribution to the Gross Domestic Product (GDP) of the country. Activities in this theatre involve (but not limited to) the conveyance of passengers, movement of animals, farm products and merchandise and the rendering of mobile services (clinics, libraries, banks, etc.). Owing to the contribution to the GDP, transport is an integral portion of most economical activities in Nigeria. It is an obvious reality that the commonest reason for hike in price of items is the rise in transportation costs.

In many developing countries, inadequate transport facilities appears to be the order of the day. However, a good transport system is essential for sustained economic growth

Published on November 19, 2020.

S. Konyeha, Department of Computer Science, Faculty of Sciences, University of Benin, Nigeria.

(corresponding e-mail: susan.konyeha ${ }^{@}$ gmail.com) and development. Since the era of independence in 1960 one major problem of Nigerian transport system is bad roads and poor maintenance thereof. In line with these are physical problems such as scarcity of adequately trained transport managers and planners, capital restructuring obstacles and ineffective traffic regulations. Many transportation system problems could be reduced by the use of Intelligent Transportation Systems (ITSs). Communication technology is a major component of Intelligent Transportation Systems (ITSs) and is responsible for the transfer of traffic data to and from different sensors in the network to and from the traffic management center some distance away.

Vehicular Ad-hoc Networks (VANETs) [2], [3] is a promising network communication technology that is expected to be deployed in the communications infrastructure for many ITS applications and thus significantly improve the performance of the transportation systems [4]. These networks as shown in Figure 6 are created by applying the principles of Mobile Ad-hoc Networks (MANETs) to the vehicle space [5]. Vehicular ad-hoc networks (VANETs) technology has been an important subject of research in recent years.

\section{RELATED LiteratURES}

\section{A. Concept of Transportation}

Transportation is the translation of people, animals and goods from one location to another. Transportation systems are means by which goods, animals and people are conveyed to or made available to where they are needed for commercial or non-commercial purposes, as at when desired. Mobility is therefore an important factor in any society if meaningful levels of social interaction, co-operation, production activities, economic and other types of development is to be realized.

\section{B. Transportation in Nigeria}

Transportation is one of the basic sectors of an economy. In developing countries, the transportation sector is among the sectors that needs serious attention and intervention.

There are four major modes of transportation, which are:

- Land transportation (via automobile either by road or rail).

- Air transportation.

- Water transportation.

- Human portage and use of animals such as camels (more common in the Northern part of Nigeria).

E. Osa, Department of Electrical and Electronic Engineering, Faculty of Engineering, University of Benin, Nigeria. (e-mail: edosa.osa@ uniben.edu) 
Of all these means of transportation, road transport seems to be the most common, the most affordable, the most easily accessible and the one that is most prone to disaster.

Most developing countries have a past of colonialism and are therefore at a disadvantage considering capacity for economic development with regards to transportation infrastructure systems. Partly because the existing road transportation systems designed by colonial masters are often out of step with modernity. Developing countries including Nigeria have inherited minimally developed roads that only connect a few major cities and were designed mainly to facilitate the transfer of commodities from colonies to ship ports for onward transfer to the colonial nations [6]. A consequence of this is that rural populations are virtually disconnected from any meaningful economic participation [6]-[8].

Road transportation infrastructure investment produces real and measurable economic impact that results from the ability of businesses to get road access to production input factors and marketplaces. Policymakers in Nigeria must therefore underscore the effects of investments in road transportation infrastructure on economic development, the drive of such investment, how much to invest and the ramifications of the investment to the wealth and power of the country. Table 1 indicates the transport sector received a substantial part (ranging from $8.6 \%$ to $23.7 \%$ ) of the planned public sector expenditure by the Nigerian Government from 1962 to 1998.
TABLE 1: Percentage Share of Planned Public Sector EXPENDITURE ON TRANSPORT SECTOR 1962-1998

\begin{tabular}{ccc}
\hline Plan & Plan Period & $\begin{array}{c}\text { \% Share of the } \\
\text { Transport Sector }\end{array}$ \\
\hline $\begin{array}{c}\text { First National } \\
\text { Development Plan } \\
\text { Second National } \\
\text { Development Plan } \\
\text { Third National }\end{array}$ & $1962-1968$ & 21.3 \\
$\begin{array}{c}\text { Development Plan } \\
\text { Fourth National }\end{array}$ & $1970-1974$ & 23.7 \\
$\begin{array}{c}\text { Development Plan } \\
\text { First National Rolling Plan } \\
\text { Second National Rolling } \\
\quad \text { Plan }\end{array}$ & $1975-1980$ & 22.2 \\
Third National Rolling & $1994-1996$ & 15.2 \\
$\quad$ Plan & $1996-1998$ & 11.6 \\
\hline Sources: Nigeria National Budget and Rolling Plans, (1962-1998).
\end{tabular}

Nigeria is therefore one of the African countries that have spent a considerable amount of their financial resources in building, expanding and modernizing her transportation infrastructure.

Table 2 shows the proportional allocation of capital expenditure to transportation sub-sector in Nigeria from 1962 to 2000 . Roads (highways) received the highest allocation from 1981 to 2000. During this period, the Government spent more on road transport than on all the other modes of transportation cumulated.

TABLE 2: PROPORTIONAL ALLOCATION OF CAPITAL EXPENDITURE TO THE TRANSPORT SUB-SECTOR 1962-2000

\begin{tabular}{|c|c|c|c|c|c|c|c|c|c|}
\hline \multirow{2}{*}{$\mathrm{S} / \mathrm{N}$} & \multirow{2}{*}{ Mode of Transport } & \multicolumn{7}{|c|}{ Plan Period } & \multirow{2}{*}{ Average } \\
\hline & & $1962-1968$ & 1970-1974 & $1975-1980$ & 1981-1985 & $1985-1989$ & 1990-1994 & $1995-2000$ & \\
\hline 1 & $\begin{array}{l}\text { Highway } \\
\text { (Road) }\end{array}$ & 54 & 58.8 & 72.4 & 70 & 72.6 & 65 & 70.2 & 66.14 \\
\hline 2 & Railway & 14 & 17 & 10.6 & 15 & 3.8 & 14.2 & 13 & 12.54 \\
\hline 3 & Port (sea) & \multirow{2}{*}{25} & \multirow{2}{*}{13} & \multirow{2}{*}{9} & \multirow{2}{*}{9} & 5.9 & 7.5 & 4.6 & 10.57 \\
\hline 4 & Waterways & & & & & 3.8 & 3.3 & 3 & 3.37 \\
\hline 5 & Air(Airports) & 7 & 11 & 8 & 6 & 5.6 & 2.6 & 2.3 & 6.07 \\
\hline \multirow[t]{2}{*}{6} & Others & N/A & N/A & N/A & N/A & 8.4 & 7.4 & 6.9 & 7.57 \\
\hline & Total & 100 & 100 & 100 & 100 & 100 & 100 & 100 & \\
\hline
\end{tabular}

Sources: Nigeria National Budget and Rolling Plans, (1962-2000).

\section{Challenges to ROAD TRANSPORTATION IN NigERIA}

\section{A. Poor State of the Roads}

This is one of the major problems to road transportation in Nigeria. Majority of the roads are dilapidated due to erosions, portholes and inadequate drainage systems. Many of the new roads are constructed using inferior materials thus leaving them to the mercy of the elements within a short period of time. The roads with the potholes and uneven edges or surfaces make transportation not only difficult and stressful but also dangerous as some of those roads form major sites of accidents.

\section{B. Poor Maintenance of the Roads}

This is actually one of the factors that lead to the poor state of the Nigerian roads. Every infrastructure no matter how durable it is when it was constructed needs to be maintained because wears and tears are inevitable so long as the infrastructure is being utilized. This is one of the expected functions of government but it is not always the outcome. In addition, procrastination in maintenance and repair the roads makes it more difficult and increases the expenses required.

\section{Syphoning of Funds}

This is a major problem to road transportation in Nigeria. This is what leads to bad roads, poor maintenance of the roads and subsequently accidents along the roads. The Federal government might sign and release funds to officials in charge but those funds may be syphoned for others selfish projects. The public officials in charge collaborate with the supposed contractors to syphon these funds into their personal accounts leaving the poor masses to suffer for their selfish agenda.

\section{Road Congestions}

It is not unusual to see the roads congested with commuters, automobiles and hawkers especially in the major cities in Nigeria like Lagos. The number of people using the roads seems to exceed the road available. The junctions are ill equipped with traffic lights and traffic officers.

\section{E. Road Accidents}

This is one of the major problems of road transportation in Nigeria. The high rate of road accidents owing to the dilapidated state of many roads in Nigeria as well as the 
carelessness of drivers and other road users is alarming. This menace has resulted in numerous fatalities as well as injuries to humans and destruction of property.

Since the 1980's Nigeria has been first on the list of African countries and sometimes the world in fatalities due to road traffic accidents. [9] had examined the causes and consequences of road traffic crashes in Nigeria. They pointed out such causes as road, vehicle and human factors [10].

The Second Quarter (Q2) 2017 road transport data for Nigeria shows that 2,503 road crashes occurred during that period. Speed violation was reported as the major cause of road crashes in Q1 and accounted for $44.44 \%$ of the total reported road crashes. Thereafter, loss of control and dangerous driving followed closely as they both accounted for $12.92 \%$ and $8.06 \%$ of the total road crashes recorded. A total of 8,270 Nigerians got injured in the road traffic crashes recorded [11]. [12].

Fig. 1 displays the top ten crash-prone roads nationwide

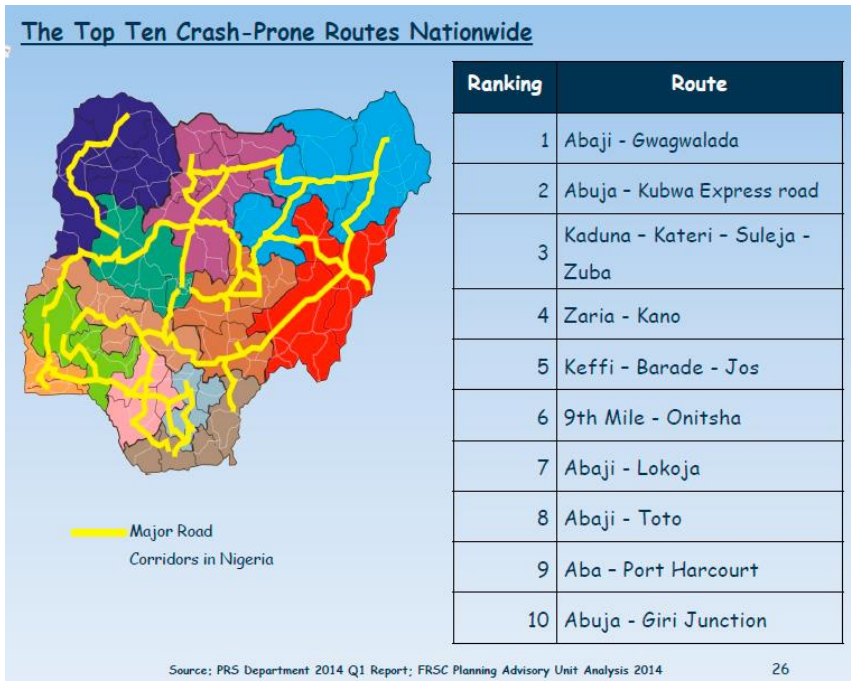

Fig. 1. Top Ten Crash -Prone Routes Nationwide.

\section{TRAFFiC MANAGEMENT}

Traffic management and enforcements on roads continue to be an issue requiring improvements. The transportation related problems found in developing countries include substandard roads, poorly maintained vehicles, bad driving habit, lack of enforcement, low literacy level of drivers, etc. The growth in the use of motor vehicles will continue on the upward exponent in urban cities as long as population growth and need for mobility and accessibility exists [13]. Hence reliable traffic management mechanisms must be put in place in terms of policy, personnel and infrastructure.

\section{Current Traffic Management Practices In NIGERIA}

Lagos State in Nigeria is the main commercial nerve centre of the country and hence is characteristic of high volume of traffic. Hence the traffic situation that prevails in this state can serve as an approximation or template for the traffic situation in country general. The Lagos State Ministry of Transportation is responsible for managing traffic through
Lagos State Traffic Management Authority (LASTMA). The Federal Government traffic agents from the Federal Roads Maintenance Agency (FERMA) and FRSC are also involved in enforcing traffic regulations on Federal roads in Lagos State. Traffic management in Lagos involves the use of human traffic agents who check out for indiscriminate parking by motorists, ensure orderly movements of vehicles at intersections, mitigate indiscriminate halts by buses at indiscriminate bus stops as well as prevent motorists from using designated lanes for Bus Rapid Transit (BRT).

LASTMA was established to address issues of deaths, injuries and economic losses from road accidents, conflicts and congestion delays on public highways in Lagos State by applying modern traffic management methods. Traffic personnel monitor traffic, check performances of traffic devices, and use mobile phones to communicate with colleagues or road users during incidents and emergencies. They also direct traffic irrespective of weather conditions and are exposed to danger of being knocked down by moving vehicles. This manner of enforcing the law on violators endangers the lives of traffic enforcer, violator and other road users, especially when the violating vehicles refuse to halt.

However inanimate objects are not prone to these dangers. Therefore if such objects can be given the necessary intelligence to carry out the duties of the traffic personnel, it will be a huge development. Enter in Intelligent Transportation System (ITS) technology used to reduce exposure of the agents to accidents, improve enforcement methods, provide information to motorists on road conditions, improve response time to highway incidents and integrate the services of traffic monitoring agency (in this case LASTMA) and other emergency services such as Fire Service, Police, Ambulance Service, etc. in real time. [14] asserted that many of the observed shortcomings in the transportation system in Lagos stem from weaknesses in management.

\section{INTELLIGENT TRANSPORTATION SYSTEMS}

Intelligent Transportation Systems (ITSs) involves the integration of modern communication and information technology into existing transportation system for real time monitoring of traffic in order to alleviate traffic congestion, incidents, public health, etc. ITSs can installed in the transportation infrastructure of highways, bridges, tunnels, railways, seaports and airports, as well as to the growing number of vehicles. USDOT-RITA, indicated various ITS application areas which include (but not limited to) crash prevention \& safety, road weather management, freeway management, roadway operations and maintenance, traffic incident management, emergency management, electronic payment and pricing, traveler information, information management, commercial vehicle operations, collision avoidance, collision notification and driver assistance. With respect to management of traffic in Lagos, any proposed ITS project will impact most of the application areas.

\section{A. Vehicular Ad Hoc Networks (VANETS)}

VANET communication infrastructure will enable ITSs to improve safety of commuters on the roads and minimize traffic congestion, waiting times, fuel consumption and 
emissions. Warning messages sent by vehicles involved in an accident can enhance traffic safety by assisting approaching vehicles to implement evasive actions as they approach the zone of accident [15], [16]. VANETs also have other nonsafety applications such as providing information about the current conditions of the transport network. Drivers can then navigate to new routes in case of road congestion, thereby saving precious time and fuel, while reducing emissions in the process [17]. VANETs are also designed to support Quality of Service (QoS) for certain applications which are time-sensitive, such as audio and video applications (that enable commuters to experience video and/or audio streaming while driving).

Owing to the structure of vehicular networks, communication enabled vehicles, roadside units, and other mobile devices communicate in an ad hoc manner. As a result, vehicles in transit can interact with other vehicles (vehicle-to-vehicle [V2V]), roadside units (vehicle-toinfrastructure [V2I]), or even hand-held mobile devices (vehicle-to-device [V2D]) via a Dedicated Short Range Communication (DSRC) system. DSRC is actually an enhanced version of the Wireless Fidelity (Wi-Fi) technology implemented in VANETs. It supports communication in vehicles and is characterized by high mobility which results in rapid topology changes. DSRC has been standardized by the IEEE 802.11p in the 1609 family called Wireless Access in Vehicular Environments (WAVE) [18].

\section{DEPLOYMENT OF THE INTELLIGENT TRANSPORTATION SYSTEM (ITS) IN NIGERIA TRANSPORT INFRASTRUCTURE}

Effective deployment of ITS technologies depends partly on knowing which technology will effectively address issues of congestion and safety the most [19]. To enhance performance of Lagos State traffic management in particular and Nigeria in general, an Intelligent Transportation System (ITS), which encompasses a wide range of wireless and wireline information and electronic technologies should be deployed.

Closed Circuit Television (CCTV) cameras could be installed on the highways to capture images and send them directly to a Traffic Management Center at a remote location. From the Traffic Management Center, traffic incidents could be detected in real time, verified from a remote location and the appropriate agency be alerted for required action. For instance, if there is any incident, the EMS, police or fire service could be alerted immediately and receive information on the exact location of the incident.

At intersections where traffic signals are installed and operational, the signals can be optimized remotely, to give green to approach lanes with high volume of traffic. The adaptive signal control system performs the adjustment of the signal timing in a determined jurisdiction, from a remote location.

A Traffic Management Center (TMC) consists of equipment which includes large screen monitors, servers, computers, and cable network that links the devices from the Center to the Field. This Computer Aided Dispatch System will use Wireless Area Networks to communicate with stations at emergency dispatch points. The field devices consist of cameras and traffic signals, sensors, which are positioned at strategic locations and thus data flows between the equipment and those from the field to the Center can be retrieved.

\section{RECOMMENDATIONS}

\section{A. Proposed Workability Conditions for the Adoption of} VANET Technology in a Developing Nation

1. DRSC sensors should be deployed in vehicles, highways and roadsides to enable the components of transportation network to intelligently communicate with one another. For example, the enabling of a cooperative intersection collision avoidance systems (CICAS) by which two or more vehicles equipped with DSRC systems would be in continuous communication at an intersection.

2. Route guidance mechanisms should be orchestrated.

3. Thorough implementation of wireless and wired communication technologies.

4. Upgrading the traffic signal controller to support traffic communication.

5. Procurement of relevant video management hardware and software applications.

6. Procurement of Closed Circuit Television (CCTV) cameras and supporting software.

7. Procurement of electronically dynamic message road signs and development of the adjoining software.

8. The construction of a good number of distributed Traffic Network Management centers in Nigeria.

9. Upgrading traffic poles to support CCTV camera installation.

10. Procurement of wireless communication network infrastructure as well as fibre optic systems for connecting the field offices and all traffic management centers.

\section{B. Developmental Considerations for Deployment of VANET in a Developing Nation}

- Technology:

The adoption and design of the VANET system and its applications in Nigeria, is primary to the development of traffic management and system. VANETs include equipment such as sensors, communication devices, detectors and global navigation satellite system. Such mechanisms should be made readily available for the desired improvements to be realized.

- Cooperative effort:

The implementation of this system will highly depend on the cooperation between Government, Industries, and Private entities. Modelling the road traffic will involve the development of models that can effectively characterize the present traffic situation in the country.

- Energy and sustainability:

Energy and power generation needed for the implementation of the proposed system must be stable and consistent.

\section{Benefits of the VANET System to Nigeria}

- Improved traffic flow and reduced delays thereby increasing operational performance by reducing congestion on roads.

- Increasing safety by providing information about accidents as well as other road conditions to commuters. 
- Enhancing convenience and mobility.

- Boosting productivity and expanding the economic and employment growth as a result of reduced delay in transport time of workers.

- Reduction in pollution and improved health conditions.

- Quick response time from police and emergency vehicles.

\section{CONCLUSION}

The use of ITS technology has improved traffic situations in urban cities of western climes that experience similar road transport problems like Nigeria. In the developed societies, road conditions have been improved and traffic controllers installed at most intersections. Hence, limited traffic personnel are exposed to highway traffic and unnecessary enforcement procedures (such as standing in front of violators vehicles to prevent escape or rear to rear vehicle collision and side swapping of violators vehicles during enforcements) are avoided. The application and deployment of ITS technology and VANET in particular, will provide benefits such as improved traffic flow, increased productivity, pollution reduction and increased response time to incidents. For effective utilization of the ITS technology concerned staff will need appropriate training for operation and sustenance of the TMC and the field devices.

In order to fully utilize the ITS technology, additional signalized intersections are required at intersections where many traffic agents are present so as to use adaptive traffic signal control, Cameras and sensors are required along the corridors to send data to the TMC, while the TMC are integrated with other centers for alert. The Government needs to enact laws that will require road users to comply with the developed traffic infrastructure. An important condition for the prosperity of this solution is that the system must be in constant operation and not be interrupted by epileptic power supply.

\section{REFERENCES}

[1] S.G. Ikya, 1993, "The Urban Transportation Problems in Nigeria", In Ikya, S.G. (ed.), Urban Passenger Transportation in Nigeria, Heinemann, Ibadan, pp. 3-27.

[2] IEEE, 2007, "Approved IEEE standard for wireless access in vehicular environments (WAVE) - networking services," IEEE Approved Std P1609.3/D23.pdf, Feb 2007.

[3] IEEE, 2015, "IEEE approved draft standard for wireless access in vehicular environments (WAVE) - networking services," IEEE P1609.3v3/D6, November 2015, pp. 1-162.

[4] A.A. Elbery, 2018, Large-Scale Modeling of Smart Cities Considering the Mutual Impact of Transportation and Communication Systems. Ph. D Thesis Virginia Polytechnic Institute and State University April, 16 2018 Blacksburg, Virginia.

[5] M.M. Zanjireh and H. Larijani, 2015. A Survey on Centralised and Distributed Clustering Routing Algorithms for WSNs. IEEE 81st Vehicular Technology Conference. Glasgow, Scotland. doi:10.1109/VTCSpring.2015.7145650.

[6] A.J. Njoh, 2012, Impact of transportation infrastructure on development in East Africa and the Indian Ocean region. Journal of Urban Planning and Development, 138(1), 1-9. doi: 10.1061/ (ASCE) UP.1943-5444.0000091.

[7] D.P. Thomas, 2013, The Gautrain project in South Africa: A cautionary tale. Journal of Contemporary African Studies, 31(1), 77-94. doi: $10.1080 / 02589001.2013 .747292$.
[8] A.B. Usman, 2014, Analysis of Condition of Rural Road Transportation Kwara State, Nigeria. European Scientific Journal, $10(5)$.

[9] J.A. Afolabi and K.T. Gbadamosi, 2017, "Road Traffic Crashes in Nigeria: Causes and Consequences" The International Journal of Transportation \& Logistics, Vol. 17, Issue 42, April, 2406 - 1069.

[10] P.C. Onokala and ,C.J. Olajide, 2019, Problems And Challenges Facing The Nigerian Transportation System Which Affect Their Contribution To The Economic Development Of The Country In The 21st Century World Conference on Transport Research - WCTR 2019, Mumbai, 26 30 May 2019.

[11] National Bureau of Statistics, 2017, Road Transport Data Q2 2017, Nigeria, http://www.nigerianstat.gov.ng.

[12] Federal Road Safety Commission (FRSC), 2014, Planning Advisory Unit Analysis. www.frsc.gov.ng.

[13] O. Osipitan, 2014, The Need for Application and Deployment of Intelligent Transportation Systems Technology in Managing Highway Corridors in Lagos, Nigeria. Proceedings of the 3rd International Conference on Infrastructure Development in Africa - Abeokuta, Nigeria, 17th-19th March, 2014.

[14] S.I. Oni, K.R. Okanlawon and C.O. Asenime, 2006, Institutional Framework for the Transformation of Transport Administration in Metropolitan Lagos in an Agenda for a New Nigeria: The Imperative of Transformation, Anifowose, R. and Babawale, T. (eds.), Concept Publications Limited, Lagos, 421- 437.

[15] ElBatt, Goel, Holland, Krishnan, and Parikh, 2006, "Cooperative collision warning using dedicated short range wireless communications," In Proceedings of the 3rd International Workshop on Vehicular Ad Hoc Networks, VANET '06, (New York, NY, USA), pp 1-9, ACM, 2006

[16] Xu, Mak, Ko, and Sengupta, 2007, "Medium Access Control Protocol Design for Vehicle Dash; Vehicle Safety Messages," IEEE Transactions on Vehicular Technology, vol. 56, pp. 499-518.

[17] S. Dashtinezhad, T. Nadeem, B. Dorohonceanu, C. Borcea, P. Kang and L. Iftode, 2004, "Traffic View: A Driver Assistant Device for Traffic Monitoring Based on Car-To-Car Communication," In 2004 IEEE 59th Vehicular Technology Conference. VTC 2004-Spring (IEEE Cat. No.04CH37514), vol. 5, pp. 2946-2950 Vol.5, May 2004.

[18] IEEE, 2014, "IEEE Guide for Wireless Access in Vehicular Environments (WAVE) - Architecture," IEEE Std 1609.0-2013, pp. 178, March 2014.

[19] R. Bertini, C. Monsere and T. Yin, 2005, Benefits of Intelligen Transportation Technologies in Urban Areas: A Literature Review. Final Report, Center for Transportation Studies, Portland State University, Oregon. 